NOAA

National Marine

Fisheries Service
Fishery Bulletin

¿ established 1881 ๙
Spencer F. Baird

First U.S. Commissione of Fisheries and founder of Fishery Bulletin
Abstract-We provide an overall description of the species composition and abundance of pelagic fish assemblages sampled with midwater trawls at depths $<100 \mathrm{~m}$ in the southeastern Brazilian Bight (SBB, south-southeastern Brazil) during the spring-summer period from 1995 through 2010. We also investigated the effect of 1) 3 water masses, the South Atlantic Central Water (SACW), Coastal Water (CW), and Mixed Water (M), and 2) a set of environmental and spatial variables on the SBB pelagic fish assemblages. The aggregations comprising 43 species, were dominated by highly abundant mid-trophic-level schooling species. The Argentine anchoita (Engraulis anchoita), rough scad (Trachurus lathami), Atlantic cutlassfish (Trichiurus lepturus), and Brazilian sardinella (Sardinella brasiliensis) were the dominant species by biomass. They were distributed widely over the SBB and occurred in all years. Results from multivariate analyses indicate that SACW and the combination of $\mathrm{CW}$ and $\mathrm{M}$ affected the SBB pelagic assemblage structure and that each contained a specific species grouping, whose abundance changed in relation to depth within the water column and to distance from shore of both SACW and $\mathrm{CW}+\mathrm{M}$. This pattern is consistent with the hydrographically complex structure of the SBB in spring and summer.

Manuscript submitted 1 February 2015. Manuscript accepted 23 February 2016. Fish. Bull. 114:220-236 (2016).

Online publication date: 15 March 2016. doi: $10.7755 /$ FB.114.2.8

The views and opinions expressed or implied in this article are those of the author (or authors) and do not necessarily reflect the position of the National Marine Fisheries Service, NOAA.

\title{
Fish assemblages on the southeastern Brazilian Bight, sampled by midwater trawl during spring and summer seasons: species composition, abundance, and environmental drivers
}

\author{
Riguel F. Contente (contact author) \\ Carmen L. D. B. Rossi-Wongtschowski \\ Email address for contact author: riguel@usp.br \\ Instituto Oceanográfico \\ Universidade de São Paulo \\ Praça Oceanográfico, 191 \\ 05508-120, São Paulo, SP, Brazil
}

The dramatic increase of human activities in coastal ecosystems worldwide has caused unprecedented losses of biodiversity and changes in the structure, resilience, resistance, and services of ecosystems (Möllmann et al., 2015). Many ecological consequences of these disturbances remain largely unclear because consistent ecological data are lacking, especially in the tropics. High biodiversity, combined with the high diversity of habitats and oceanographic dynamics in tropical and subtropical areas, induces complex spatiotemporal patterns in fish assemblages (Longhurst and Pauly, 2007). Such complexity makes traditional fishery management based on monospecific population models inadequate and emphasizes the need to control tropical fisheries on the basis of an ecosystembased fisheries management (EBFM) perspective (Vasconcellos and Gasalla, 2001; Curtin and Prellezo, 2010). The first step toward achievement of strong EBFM is to know how fish species respond to the oceanographic environment and its dynamism (Longhurst and Pauly, 2007; Curtin and Prellezo, 2010; Harding et al., 2011; Litz et al., 2014).
The largest fish aggregations (defined here as a large multispecific group of fishes that gather together, for behavioral or other reasons) on continental shelves are generally dominated by small pelagic fish species, such as sardines and anchovies, that are usually short-lived, planktivorous fishes frequently associated with areas of high productivity (Brodeur et al., 2005; Harding et al., 2011; Litz et al., 2014). These species are ecologically and economically important, exerting bottom-up, top-down, and wasp-waist control in shelf food webs (Cury et al., 2000; Speckman et al., 2005) and supporting valuable fisheries (Vasconcellos and Gasalla, 2001). The presence and abundance of small pelagic fishes are particularly sensitive indicators of changing oceanographic and climatic conditions, migrating quickly into their preferred habitat or responding with pronounced recruitment fluctuations over relatively short time intervals (Brodeur et al., 2003; Brodeur et al., 2005; Longhurst and Pauly, 2007).

In spite of being a western boundary system, the large marine ecosystem of the southeast South American shelf (SSAS; sensu Bisbal, 1995) presents productivity hotspots comparable to those of eastern bound- 

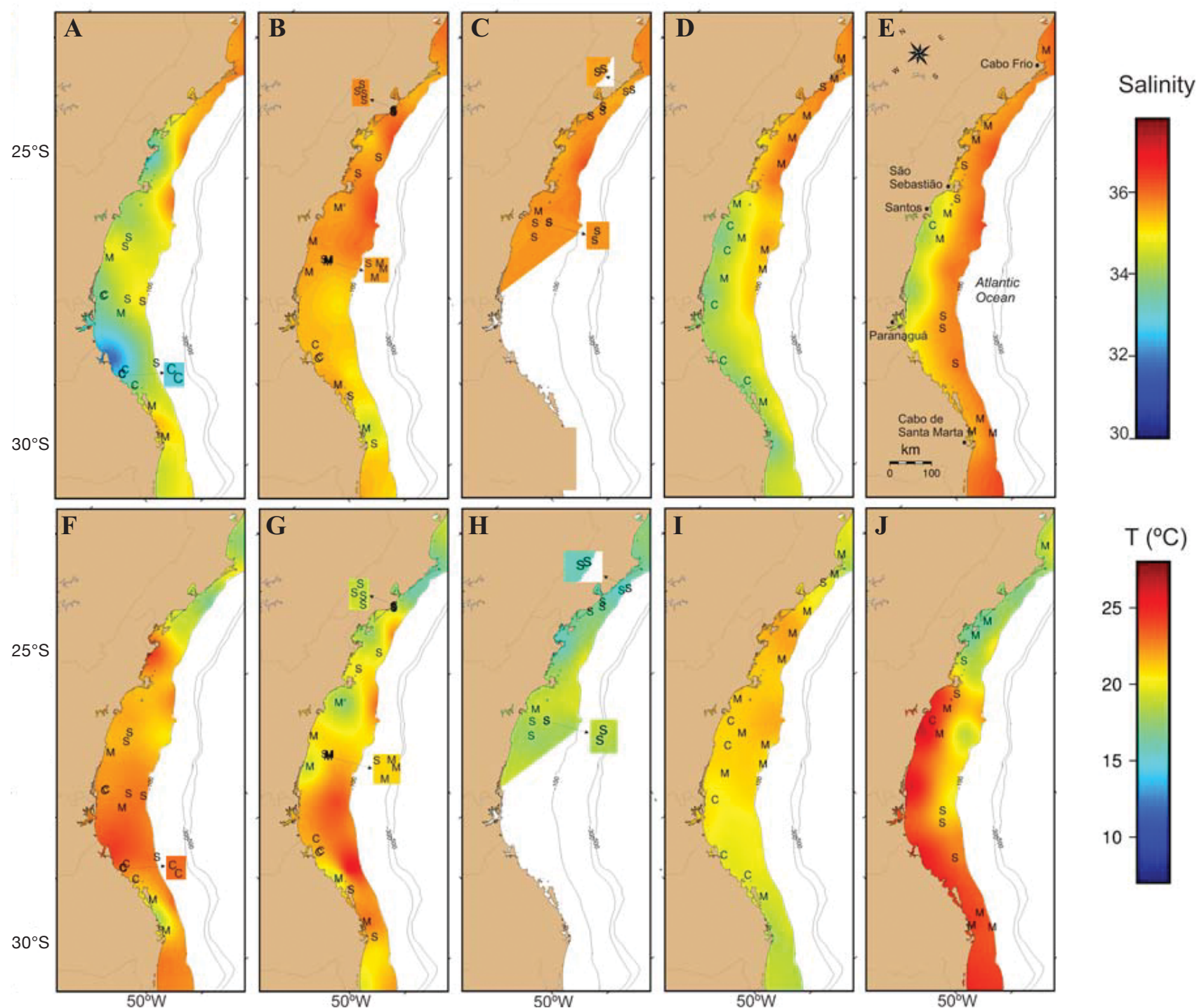

Figure 1

Maps of salinity and temperature (T) values collected at the mean depth of the fish aggregations at the water column and the locations of each midwater tow of each of 5 cruises of the Program ECOSAR (translates from Portuguese as "Prospecting to investigate sardine biomass by acoustic methods") in the southeastern Brazilian Bight off southeastern Brazil: (A) and (F) ECOSAR III (18 November-2 December 1995), (B) and (G) ECOSAR IV (20 January-2 February 2008), (C) and (H) ECOSAR V (8-24 November 2008), (D) and (I) ECOSAR VI (22 September-8 October 2009), and (E) and (J) ECOSAR VII (3-22 March 2010). Tows are codified according to the water masses in which it was accomplished: Coastal Water (C), South Atlantic Central Water (S), and Mixed Water (M), an area of mixing of water masses. For the range and mean of depths for these cruises, see Table 3. Because these maps show mean depths, depths of some tows may have fluctuated around the mean; therefore, there should be cases where the code of the water mass of tow and the temperature and salinity gradient do not correspond. Zoomed-in images are provided to show points of overlapping tows.

ary upwelling ecosystems (Lopes et al., 2006b). These hotspots are driven by substantial nutrients from oceanographic features, such as the Subtropical Shelf Front, the Rio de La Plata plume, the Patagonian tidal front, and coastal upwellings (Bisbal, 1995; Ciotti et al., 2014).

The coastline of southeastern Brazil (the northern sector of SSAS) from Cabo Frio $\left(22^{\circ} 52^{\prime}\right.$ S $)$ to Cabo de
Santa Marta Grande (28 $\left.40^{\prime} \mathrm{S}\right)$ forms the southeastern Brazilian Bight (SBB) (Fig. 1). Three water masses occur frequently in the SBB: the high-salinity and nutrient-rich South Atlantic Central Water (SACW) (temperature $[\mathrm{T}]<18.5^{\circ} \mathrm{C}$, salinity $[\mathrm{S}]=35.3-36.0$ ); the warm nutrient-poor Tropical Water $\left(\mathrm{T}>18.5^{\circ} \mathrm{C}, \mathrm{S}>36.0\right)$; and the low-salinity mesotrophic Coastal Water (CW; $\mathrm{T} \geq 18.5^{\circ} \mathrm{C}, \mathrm{S}=34.0-35.3$ ); the latitudinal and bathymet- 
ric locations of these water masses change seasonally (Castro and Miranda, 1998; Ciotti et al., 2014). Like a typical subtropical shelf ecosystem, the SBB exhibits a strong seasonal signal of stratification (Castro, 2014) and pelagic fertilization (Lopes et al., 2006a).

In autumn and winter, the increased frequency and strength of southwest winds (i.e., downwelling-favorable winds) due to recurrent passages of atmospheric frontal systems (Ciotti et al., 2014) favor strong vertical homogeneity, the distance of $\sim 86 \mathrm{~km}$ of the SACW from shore, the predominance of the $\mathrm{CW}$ and Tropical Water on the SBB, and, eventually, the northward displacement of the low-salinity and nutrient-rich Rio de La Plata plume up to the southern part of the SBB (Ciotti et al., 2014). In contrast, in spring and summer, both the prevailing northeast winds (Ciotti et al., 2014) and the higher frequency of cyclonic meanders of the Brazil Current (Campos et al., 1995) favor cross-shelf SACW intrusions toward the coast. Also in spring and summer, continental runoff generally is higher than that during other seasons, and increased runoff may make the $\mathrm{CW}$ expand offshore and occur nearer the ocean surface on the SBB (Lopes et al., 2006a). Such processes lead to strong vertical and geographic variability in temperature and salinity because of the presence of 2 markedly different water masses (CW and SACW) in the spring and summer (Castro, 2014; Ciotti et al., 2014; Fig. 1). In spite of this stratification, the interface zones between the $\mathrm{CW}$, the SACW, and the offshore Tropical Water, in association with natural localized mixing, produce a Mixed Water (M) mass (Castro, 2014).

This spring-summer oceanographic structure (Castro, 2014) increases oceanic fertilization, pelagic productivity (Lopes et al., 2006a), and water column stability, and all such conditions synergistically enhance the larval survival of many fish species that spawn at this time, including important commercial species, such as the Brazilian sardinella (Sardinella brasiliensis) (Katsuragawa et al., 2006). Therefore, it is expected that the structure of the pelagic fish assemblage would respond to these typical spring-summer water masses and to their spatial variability.

The SBB produces approximately 50\% of Brazil's marine landings (MPA ${ }^{1}$ ), and the Brazilian sardinella is the main species landed (UNIVALI ${ }^{2}$ ). Despite the ecological and economic importance of the SBB, our understanding of the ecological patterns of its shallow (depths $<100 \mathrm{~m}$ ) pelagic aggregations is still fairly limited because of 1) the limited number of surveys with pelagic trawls in comparison with other sampling gears, such as bottom trawls (e.g., Rocha and RossiWongtschowski, 1998; Rossi-Wongtschowski et al.,

\footnotetext{
${ }^{1}$ MPA (Ministério da Pesca e Aquicultura). 2011. Boletim estatístico da pesca e aquicultura 2011,59 p. MPA, Brasilia, Brazil. [Available at website.]

2 UNIVALI (Universidade do Vale do Itajaí). 2011. Boletim estatístico da pesca industrial de Santa Catarina-Ano 2010, 59 p. Centro de Ciência tecnológicas da Terra e do Mar, UNIVALI, Itajaí, Brazil. [Available at website.]
}

2008) - a situation that is a general one for the whole SSAS (e.g., Haimovici et al., 1994; Jaureguizar et al., 2006), and 2) the focus of most pelagic trawl surveys on a single species (e.g., Brazilian sardinella; Johannesson $^{3}$; Rijavec and Amaral ${ }^{4}$; Castello et al., 1991). These biases limit our understanding of the functioning of this large regional-scale $(<1000 \mathrm{~km})$ ecosystem and its changes due to climate changes and fisheries, therefore limiting our ability to implement strong EBFM.

During the Program of Assessment of the Sustainable Potential of the Living Resources in the Exclusive Economic Zone (REVIZEE), acoustic surveys and pelagic trawls were conducted off the SBB at depths $>100$ m (Madureira et al., 2005; Soares et al., 2005). Between 1995 and 2010, this sampling procedure was adopted to sample pelagic aggregations and the oceanographic environment in the SBB at depths $<100 \mathrm{~m}$ during 7 cruises for the Program ECOSAR (abbreviation translated as: Prospecting to investigate sardine biomass by acoustic methods). The checklist of species from all of these cruises (Rossi-Wongtschowski et al., 2014) and the pattern of species abundance for ECOSAR II and III cruises (Soares et al., 2005) are already available.

In this study, we synthesized the data of ECOSAR III-VII cruises conducted in spring and summer 1) to provide an overall description of the species composition and abundance of the fish aggregations in the SBB during the spring and summer and 2) to investigate how these aggregations respond to the typical springsummer water masses (CW, SACW, and M) and to a set of environmental and spatial covariates to such water masses.

\section{Materials and methods}

\section{Sampling procedures}

Fish and oceanographic data for this study were obtained in the spring or summer between 1995 and 2010 during the ECOSAR III, IV, V, VI and VII cruises on board the RV Atlântico Sul of the Federal University of Rio Grande. The search for fish aggregations was conducted over a pre-established grid during the day and night, at a mean speed of $5.1 \mathrm{~m} / \mathrm{s}$ (10 knots), over a period lasting from 12 to 18 days. A grid of parallel transects was used, with a distance of $37 \mathrm{~km}$ between them. The grid spanned from the Cabo Frio (Rio de Janeiro, north limit) to Cabo de Santa Marta (Santa Catarina, south limit) (Fig. 1) and included depths from 20 to 102

\footnotetext{
${ }^{3}$ Johannesson, K. A. 1975. Relatório preliminar das observações acústicas quantitativas sobre tamanho e distribuição dos recursos de peixes pelágicos ao largo da costa sul do Brasil. Programa de Pesquisa e Desenvolvimento Pesqueiro do Brasil Série Documentos Técnicos 10, 27 p.

4 Rijavec, L., and J. C. Amaral. 1977. Distribuição e abundância de peixes pelágicos na costa sul e sudeste do Brasil: (resultados da pesquisa com ecointegrador) 2 cruzeiros. Programa de Pesquisa e Desenvolvimento Pesqueiro do Brasil Série Documentos Técnicos 24, 55 p.
} 
m. Pre-established, fixed stations were determined on the grid to map the salinity and temperature patterns for the entire study area. To interpolate suitably among stations, the coverage level of the cruises was calculated as the ratio between the prospected distance, in kilometers, and the total area (Soares et al., 2005). The acoustic data were collected with a Simrad EK500 5 scientific split-beam echosounder (Simrad Fisheries, Lynnwood, WA) operating at 38 and $120 \mathrm{kHz}$. Such data were not used in this study and are available in Soares et al. (2005) and Madureira et al. (2005).

When schools were detected (during the day or night), the midwater net was deployed at the mean depth of the school. The tension and the length of the cables of the midwater net and the boat speed were changed frequently whenever the target reacted, and therefore the position of the net in the water column was correspondingly modified. The net performance and the mean depth of the net operation were measured with a Simrad FR500 probe (Trawl Eye system; Simrad Fisheries) located at the upper part of the net. The mean depth of net operation was considered the mean net depth between the beginning and the end of the haul (i.e., mean depth of the fish aggregation at the water column) and is referred to in this article as $Z_{\text {a }}$. The hauls were performed against the wind and current at, on average, speeds between 1.5 and $2 \mathrm{~m} / \mathrm{s}$ (3 and 4 knots) for a period of time depending on the size and reaction of the schools. Boat speed was measured in relation to the sea bottom. For more details on the determination of grid sizes, sampling methods, and procedures of fisheries operations, see Soares et al. (2005) and Madureira et al. (2005).

A net designed especially for fishing small pelagic fish was used. It had a squared opening (sides of $15 \mathrm{~m}$ ) and mesh of $400 \mathrm{~mm}$ between knots in the wings and square. The mesh gradually decreased from $50 \mathrm{~mm}$ in the tunnel to $20 \mathrm{~mm}$ in the bag, which was covered internally by a panel of mesh. The net was kept open by 2 doors (Suberkrub type) of $4 \mathrm{~m}^{2}(3 \mathrm{~m} \times 1.35 \mathrm{~m})$, weighing approximately $380 \mathrm{~kg}$ each.

The salinity and temperature were measured with a conductivity, temperature, and depth (CTD) profiler: SBE 19 SeaCAT (Sea-Bird Electronics Inc., Bellevue, WA) during the ECOSAR III cruise and Ocean Seven 316 CTD (IDRONAUT S.r.l, Brugherio, Italy) during the ECOSAR IV-VII cruises. Measurements were taken at each 5-m depth during the ECOSAR III cruise and at each 1-m depth during the other cruises.

During the ECOSAR IV, V, VI, and VII cruises, the local depth and geographic positions were taken at the beginning and at the end of the hauls. For the ECOSAR III cruise, only the geographic position and the local depth at the beginning of the haul were taken. For all cruises, the duration of tow ( $\Delta t$ in seconds) was taken. Because of a technical problem, the mean tow

\footnotetext{
${ }^{5}$ Mention of trade names or commercial companies is for identification purposes only and does not imply endorsement by National Marine Fisheries Service, NOAA.
}

speed ( $v t$ in meters per second) for all tows was available only for ECOSAR III cruise.

The catch of each haul was weighed, and a random subsample was taken and frozen on board when large hauls were captured (>500 individuals). In this case, the weight of each species was estimated on the basis of their proportions in the subsample. Benthic and demersal species typically found on the seafloor were infrequently caught when the bottom of the net reached the seafloor, and they were found in low abundance. Because this net was not designed specifically to sample such fish, abundance estimates for these species may have been biased. Therefore, they were not considered in this study. The taxonomic identification guides used are listed in Rossi-Wongtschowski et al. (2014). Vouchers were stored at the Zoology Museum of the University of São Paulo. Rossi-Wongtschowski et al. (2014) provided a complete list of species, including the records from the benthic and demersal species, records from hauls not considered in the study discussed in this article (see below), and records from purse seine operations concurrently operated with a midwater net during some trawls.

\section{Analysis procedures}

Abundance estimates and classification of fish samples Fish biomass was the abundance metric, and values of fish biomass were standardized to a volume (cubic meters) for all hauls to incorporate the differences in tow distance and duration (Harding et al., 2011). The volume of water was calculated as follows: distance of haul ( $D$ in meters) xarea of the opening of the net $\left(268 \mathrm{~m}^{2}\right)$. In the ECOSAR IV, V, VI, and VII cruises, $D$ was calculated by using loxodromic lines based on the latitude and longitude at the beginning and at the end of the hauls (Freire and Vasconcellos, 2011). Because we did not have these geographic variables for the ECOSAR III cruise, $D$ was estimated on the basis of $v t$ as $D=v t \times \Delta t$.

We used the salinity and temperature values that were estimated through interpolation from the records of the nearest neighboring stations at the same depth of tow. Interpolations were conducted with nominal kriging, a geostatistical procedure that weights values collected at surveyed points according to a covariance function to predict a value for an unmeasured location, by using GeoR (Ribeiro and Diggle ${ }^{6}$; Diggle and Ribeiro, 2007) in $\mathrm{R}$ software, vers. 3.1.0 ( $\mathrm{R}$ Core Team, 2014). Because of technical issues during the ECOSAR $\mathrm{V}$ cruise, salinity and temperature were not regularly measured along the grid (Fig. 1). As a result of this lack of data, we removed fish samples from the southern SBB.

The fish samples from the 78 tows considered in this study were not equally distributed over the entire length of the SBB (Fig. 1) or over the cruises and water

\footnotetext{
${ }^{6}$ Ribeiro, P. J., Jr., and P. J. Diggle. 2001. GeoR: a package for geostatistical analysis. R News 1(2):15-18. [Available at website.]
} 


\section{Table 1}

Number of tows per water mass for each of 5 cruises (III-VII) of the Program ECOSAR (translates from Portuguese as "Prospecting to investigate sardine biomass by acoustic methods"). The water masses included the South Atlantic Central Water (SACW), Coastal Water (CW), and Mixed Water (M).

\begin{tabular}{lrrrrr}
\hline & \multicolumn{5}{c}{ Cruise } \\
\cline { 2 - 6 } Water mass & III & IV & V & VI & VII \\
\hline SACW & 5 & 9 & 10 & 1 & 5 \\
CW & 6 & 3 & 0 & 5 & 1 \\
M & 4 & 8 & 2 & 11 & 8 \\
Total & 15 & 20 & 12 & 17 & 14 \\
& & & & & \\
\hline
\end{tabular}

masses (Table 1) because of the different selections of samples, operational constraints, weather conditions, and other aims of the surveys. Nevertheless, fish sampling covered the entire length of the SBB in most of the cruises (Fig. 1).

The water mass, either SACW or CW, in which each tow was carried out was identified on the basis of the mean temperature and salinity recorded at the mean depth of tow. Any record of salinity or temperature outside the usual bounds for these water masses may be indicative of mixing processes among SACW, CW, or Tropical Water; therefore, the water mass for such records was classified as M.

Species composition and abundance The frequency of abundance (biomass) for each species for each cruise $(\% \mathrm{~B})$, total frequency of abundance for all cruises $\left(\% \mathrm{~B}_{\mathrm{T}}\right)$, and total frequency of occurrence $\left(\% \mathrm{FO}_{\mathrm{T}}\right.$; i.e., the number of occurrences of the species in relation to the total 78 tows) was calculated to infer the characteristics of the structure of the fish aggregations and assemblages.

The effect of water masses on the fish assemblage structure After we assigned each of the tows to one of the water masses ( $\mathrm{CW}$, SACW, and $\mathrm{M}$ ), the following procedures were performed to construct the response biomass matrix: 1) species occurring in $<3 \%$ of tows were removed from the data set because they may have added noise rather than information to the statistical solutions (Legendre and Legendre, 1998) and 2) the abundance data were first transformed in order to scale reduction due to high species-specific abundance variability among fish samples. As a result, the resulting matrix contained 78 tows and 36 species.

A nonparametric, permutational multivariate analysis of variance (PERMANOVA; Anderson et al., 2008) was used to test for differences in fish assemblages among water masses (factor fixed, with 3 levels: CW, SACW, M) and among the cruises (factor random, with 5 levels: ECOSAR III, IV, V, VI, VII cruises). In brief,
PERMANOVA (analogous to multivariate analysis of variance [MANOVA] ) is a routine that calculates the pseudo- $F$ statistic for testing the response of variables (the response biomass similarity matrix) to factors in an analysis of variance experimental design on the basis of any resemblance measure. Unlike tests where multinormality is assumed (e.g., MANOVA), PERMANOVA obtains the significance of the test statistic by permutation. Therefore, this routine was quite suitable for our data that were not normally distributed (Anderson et al., 2008).

Because our design was unbalanced (Table 1), we used type-I sums of squares to conduct the partitioning the variability of the total species data. A potential problem in an unbalanced design is that the order in which the terms of the main PERMANOVA model are inserted into the analysis may affect the result because the terms are not independent of one another. Therefore, we changed the order of main-effect terms and verified how this different change in order affected the results (Anderson et al., 2008). Terms of the main model with negative components of variation were taken as probably having zero variance and, for that reason, were eliminated from the analyses and the data were re-analyzed (Fletcher and Underwood, 2002). A posthoc permutational $t$-test from the PERMANOVA routine was then applied to compare levels of the fixed factor (water mass) when it was significant.

The method of PERMANOVA is sensitive to differences in within-group dispersions. A significant result for a given factor for PERMANOVA could signify that the groups differ in their location in multivariate space, in their dispersion in it, or a combination of the 2 (Anderson et al., 2008). Therefore, we used the permutational analysis of multivariate homogeneity of dispersions (PERMDISP), which is a distance-based test of homogeneity of multivariate within-group dispersions among groups of a single factor. A significant result of PERMANOVA and a nonsignificant effect of PERMDISP indicate that there is a genuine difference in location among the groups in the multivariate space (i.e., that there is a significant effect of factor). The PERMANOVA and PERMDISP routines were based on the Bray-Curtis similarity index and their significance on 9999 permutations.

Similarity percentages analysis (SIMPER) was applied with a cumulative contribution cutoff level of $90 \%$ to determine which species contributed to differences in fish assemblage structure among the water masses (Clarke and Warwick, 2001).

These analyses were performed with the software PRIMER 6, vers. 6.1.11, with the add-on package PERMANOVA+, vers. 1.0.1 (PRIMER-E Ltd., Ivybridge, $\mathrm{UK})$.

The effect of environmental and spatial factors on the fish assemblage structure We assessed the relationship between the variability in the fish assemblage structure and the oceanographic and spatial variables (Table 2). This analysis was based on 2 matrices. The first matrix 


\section{Table 2}

Means, ranges, and measurement sources of oceanographic and spatial factors sampled during ECOSAR IV-VII cruises and used as explanatory variables in the analysis conducted with the distancebased nonparametric linear modeling (available in DistLM in the PERMANOVA+ add-on for the software PRIMER 6). Eventual transformations before regression also are provided. Standard deviations $(\mathrm{SDs})$ of the means are provided in parentheses. $x=$ variable; na=not applicable; $Z=$ local depth; $Z_{\mathrm{a}}=$ mean depth of the fish aggregation at the water column; CTD=conductivity, temperature, and depth.

\begin{tabular}{lcclc}
\hline Variable & Mean (SD) & Range & Source & Transformation \\
\hline Latitude $\left(^{\circ}\right)$ & na & $22.6-28.6$ & GPS & \\
Longitude $\left(^{\circ}\right)$ & na & $41.7-48.6$ & GPS & \\
Distance from shore $(\mathrm{km})$ & $31.7(28.5)$ & $1.0-132.0$ & Satellite & $\ln (x+1)$ \\
$Z$ local $(\mathrm{m})$ & $47(20)$ & $20-102$ & Echosounder & \\
$Z$ bottom $(\mathrm{m})^{1}$ & $10(14)$ & $0-53$ & Echosounder & $\ln (x+1)$ \\
$Z$ a $(\mathrm{m})$ & $24(14)$ & $11-84$ & Echosounder & $\ln (x+1)$ \\
Chlorophyll- $a\left(\mathrm{mg} / \mathrm{m}^{3}\right)^{2}$ & $2.06(2.00)$ & $0.30-6.30$ & Satellite & $\checkmark x$ \\
Bottom salinity & $35.38(0.60)$ & $33.80-36.00$ & CTD profiler & $\sqrt{ } x$ \\
Surface salinity & $34.58(1.68)$ & $28.70-36.60$ & CTD profiler & $\ln (x+1)$ \\
Bottom temperature $\left(\mathrm{T}^{\circ} \mathrm{C}\right)$ & $17.90(3.06)$ & $12.90-26.00$ & CTD profiler & \\
Surface temperature $\left(\mathrm{T}^{\circ} \mathrm{C}\right)$ & $23.47(2.07)$ & $18.70-28.60$ & CTD profiler & \\
\hline
\end{tabular}

${ }^{1}$ Distance from the seafloor to the bottom of the net.

${ }^{2}$ Satellite-derived data for surface levels of chlorophyll- $a$ averaged over the period of the cruise were taken from the Moderate Resolution Imaging Spectroradiometer (MODIS) data set available from NASA. Available from website, accessed April 2015). Data are available with 8-day temporal resolution and 4-km spatial resolution. Therefore, we used data averaged over the period of the cruise.

was the same response matrix used in PERMANOVA, but it was reduced to 63 tows and 31 species because 1) the data from the ECOSAR III cruise were not considered because we did not have satellite chlorophyll$a$ data available for the period of this cruise, and 2) species occurring in $<3 \%$ of the tows of the resulting matrix were excluded. The second matrix was one of environmental and spatial variables (matrix of predictors), containing 63 samples and 11 variables (Table 2 ). The abundance data of the response biomass matrix were previously transformed to scale reduction.

This removal of data from the ECOSAR III cruise did not affect the relation between the conclusions drawn from the results of PERMANOVA and SIMPER and those drawn from the analyses described below. This relation was not affected because we obtained practically the same results (not shown) in repeating the PERMANOVA and SIMPER analyses without the data from the ECOSAR III cruise.

The relationship between species and their environment was assessed by using the distance-based, nonparametric linear modeling available in DistLM (Anderson et al., 2008) in the PERMANOVA+ add-on (vers. 1.0.1) for the software PRIMER 6, vers. 6.1.11. This routine fits predictor variables (matrix of predictors) to a set of response variables (the response biomass similarity matrix) on the basis of any resemblance measure (Anderson et al., 2008). Unlike the multivariate regressions where multinormality is assumed, this routine tests the null hypothesis of a no species-environment relationship through permutation (Anderson et al., 2008), making it quite suitable for our data that were not normally distributed. Moreover, the flexibility of the routine to run on any resemblance measure allowed the use of the Bray-Curtis index (Anderson et al., 2008), which best described the distribution of species abundance in our data (Legendre and Legendre, 1998; Clarke and Warwick, 2001). The significance of test results was based on 9999 permutations.

To meet the assumption of linearity of model, (Anderson et al., 2008), before running DistLM, we checked for outliers and skewness in draftsman plots among the predictors, transforming them when necessary (Table 1; Legendre and Legendre, 1998). We also removed one redundant predictor when correlated (Pearson's correlation coefficient $[r]$ ) at $r \geq 0.70$ (Dormman et al., 2013) with another one. We used information criteria to choose the most parsimonious model, in other words, the simplest model (the one with the lowest number of predictors) with enough suitable explanatory power (Burnham and Anderson, 2002). We based our selection on both the corrected Akaike information criterion $\left(\mathrm{AIC}_{\mathrm{c}}\right)$ and the Bayesian information criterion (BIC) (Burnham and Anderson, 2002). The model selection procedure best, available in the software PRIMER 6, provided the 20 best models. Balancing the severity of the BIC with the flexibility of the AICc to include variables in models has been shown to be a robust selection procedure (for more details, see Anderson et al., 2008). The following steps were conducted to select a model: the number of variables in the model was defined as the number of variables most frequently found among 
Table 3

Minimum (Min), maximum (Max), and mean depth $\left(Z_{a}\right)$ of the fish aggregations at the water column and the distance from shore for ECOSAR III-VII cruises. Standard deviations (SDs) of the means are presented in parentheses

\begin{tabular}{|c|c|c|c|c|c|c|}
\hline \multirow[b]{2}{*}{ Cruise } & \multicolumn{3}{|c|}{$Z_{a}(\mathrm{~m})$} & \multicolumn{3}{|c|}{ Distance from shore $(\mathrm{km})$} \\
\hline & Min & $\operatorname{Max}$ & Mean (SD) & Min & Max & Mean (SD) \\
\hline III & 7.5 & 60 & $24.4(14.6)$ & 4.0 & 113.8 & $38.9(35.5)$ \\
\hline IV & 11 & 55 & $20.6(10.3)$ & 2.6 & 51.7 & $22.9(16.6)$ \\
\hline V & 13 & 84 & $32.6(22.4)$ & 2.8 & 78.0 & $27.7(25.0)$ \\
\hline VI & 12 & 34 & $19.6(6.1)$ & 1.0 & 132.2 & 38.7 (38.6) \\
\hline VII & 12 & 58 & 29.0 & 4.2 & 100.2 & $38.5(30.2)$ \\
\hline
\end{tabular}

the 20 most parsimonious models according to both criteria. Then, that model was chosen that had the lowest BIC value among those models with the number of variables defined above (Anderson et al., 2008).

The influence of the predictor variables of the selected model on the variation in fish assemblage structure was visually assessed by the constrained ordination distance-based redundancy analysis (dbRDA) (Anderson et al., 2008). Vectors on dbRDA ordination determine the strength and direction of the relationship between the predictors and the ordination axes. The length of the vectors was set proportionally to $r$, and their direction indicated the direction of the greatest increase in the variable. To explore the relationship between species and predictors, both species and predictor variable vectors were shown on the ordination. Only species showing a Spearman correlation coefficient $\left(\left|r_{\mathrm{SP}}\right|\right) \geq 0.2$ (Willis and Anderson, 2003) with one or more axes were displayed.

The pattern of species association We performed a cluster analysis 1) to detect potential groupings of species on the basis of their frequency of co-occurrence and 2) to explore the relation of these groupings with the significant predictors, plotting the groupings on the $\mathrm{dbR}$ DA ordination. Therefore, we used the same response matrix as that which we used for DistLM, reducing the number of species to include only those species contributing to (arbitrarily) 93\% of the relative total frequency of occurrence. The data were transformed into presence and absence, and an R-mode cluster was constructed on the basis of a matrix of similarities with the Ochiai algorithm (Podani, 2000) and distances calculated by group-average sorting. The species groupings were arbitrarily defined at a cutoff level of $20 \%$ similarity.

\section{Results}

\section{Abiotic variables}

Fish sampling sites were in areas of the SBB at depths from 20 to $103 \mathrm{~m}$ (mean per cruise: $46.5 \mathrm{~m}$ [standard deviation (SD) 20.9]). The tows were, on average, located from 22.9 to $38.8 \mathrm{~km}$ offshore, with the nearest tow at $1 \mathrm{~km}$ from the shore and the farthest tow at $132 \mathrm{~km}$ (Fig. 1, Table 3). The values for $Z_{\text {a }}$ ranged from $19 \mathrm{~m}$ to $32 \mathrm{~m}$, with the shallowest aggregation at 7.5 $\mathrm{m}$ (ECOSAR III cruise) and the deepest aggregation at $84 \mathrm{~m}$ (ECOSAR V cruise) (Table 3). During most tows $(60.5 \%)$, the net was hauled more than $3 \mathrm{~m}$ above the bottom (with a mean distance of $16.4 \mathrm{~m}$ [SD 14.4]) from the bottom of the net to the seafloor, and, during 6 tows (7.7\% of all tows), the net was hauled from 1 to $3 \mathrm{~m}$ from the bottom. The net reached the bottom in $32 \%$ of the hauls.

The number of fish samples taken in each water mass varied among the ECOSAR cruises (Fig. 2). Of the 78 fish samples taken during the cruises, $43 \%$ were collected in SACW, $32 \%$ were captured in M, and $24 \%$ were taken in CW (Fig. 2).

\section{Species composition and abundance}

In the valid samples used in this study, 43 species from 23 families were recorded (Table 4). Carangidae was the most speciose family (9 species), followed by Engraulidae (5 species). The Argentine anchoita (Engraulis anchoita [Engraulidae]), rough scad (Trachurus lathami [Carangidae]), Atlantic cutlassfish (Trichiurus lepturus), Brazilian sardinella, and flying gurnard (Dactylopterus volitans) were the most abundant species (70\% of the total biomass sampled). These 5 species, together with the Atlantic chub mackerel (Scomber colias [Scombridae]), gray triggerfish (Balistes capriscus [Balistidae]), American coastal pellona (Pellona harroweri [Pristigasteridae]), piquitinga anchovy (Anchoa tricolor [Engraulidae]), and harvestfish (Peprilus paru [Stromateidae]), accounted for $91 \%$ of the total biomass sampled (Table 4). The predatory Atlantic cutlassfish was the most common species in the sampled aggregations (Table 4).

Large schools of Argentine anchoita and rough scad dominated the biomass of the aggregations and were moderately common during the ECOSAR cruises $\left(F O_{\mathrm{T}}=\sim 41 \%\right.$ and $26 \%$, respectively; Table 4$)$. This find- 


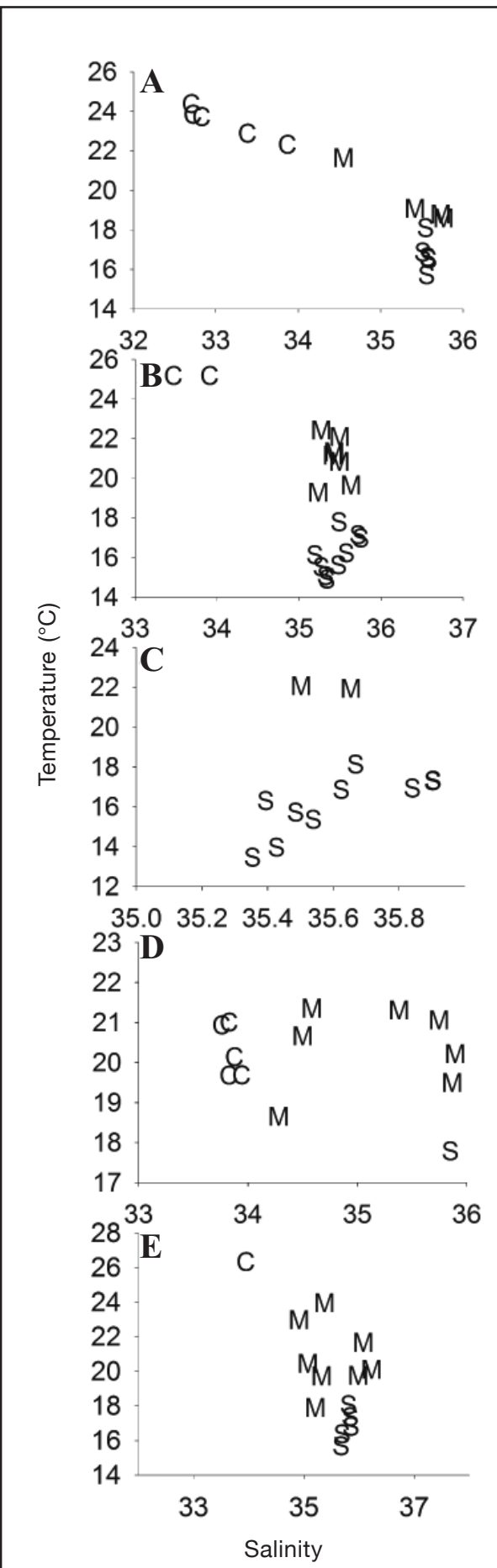

Figure 2

Plots of mean temperature versus mean salinity used for identification of the water masses at the mean depth where the tows were conducted during the spring-summer ECOSAR cruises: (A) III, (B) IV, (C) V, (D) VI, and (E) VII. The water masses are Coastal Water (C), South Atlantic Central Water (S), and Mixed Water (M) ing indicates a wide distribution and persistency over the SBB and over the years of this study (1995-2010). The Atlantic cutlassfish and Brazilian sardinella, also abundant, displayed high frequency in the aggregations over the years $\left(F O_{\mathrm{T}}=70 \%\right.$ and $51 \%$, respectively), also indicating wide distribution and persistency (Table 4). Large schools of the flying gurnard were relatively common in aggregations from 4 cruises, IV-VII (i.e., from 2008 through 2010 ), having been captured principally ( $68 \%$ of 25 tows) at midwater depths ( $>3 \mathrm{~m}$ above the bottom) and secondarily $(32 \%)$ on the bottom $(<3 \mathrm{~m})$. Large schools of the Atlantic chub mackerel ( $\sim 3$ metric tons [t], cruise IV), gray triggerfish $(\sim 0.7 \mathrm{t}$, cruise III), American coastal pellona ( $0.6 \mathrm{t}$, cruise VI), and bluefish (Pomatomus saltatrix; $~ 0.2 \mathrm{t}$, cruise V) were dominant in aggregations during only one cruise (Table 4). The other species showed both low abundance and low frequency (Table 4), reflecting either association with dominant species or scattered, low-biomass groupings.

\section{The effect of water masses on fish assemblage structure}

We found significant differences in the structure of fish assemblages among the water masses, but not among the ECOSAR cruises (Table 5). This result was not affected by changes in the order of insertion of terms of the PERMANOVA model (Table 5). Moreover, this significant result was due to the location (which indicated difference) of the fish assemblage structure of each water mass in multivariate space rather than to differences in the dispersion within assemblages of each cruise (PERMDISP, $F_{1,76}=4.16, P>0.05$ ). The posthoc permutational $t$-test revealed that the assemblage structure of SACW differed significantly from those of $\mathrm{CW}$ and $\mathrm{M}$ (SACW $\times \mathrm{CW}: t=14.12, P=0.013$; $\mathrm{SACW} \times \mathrm{M}$ : $t=14.79, P=0.003$ ), but the assemblage structures of the remaining 2 water masses did not differ significantly $(\mathrm{CW} \times \mathrm{M}: t=0.94, P>0.05)$. Consequently, the data of $\mathrm{CW}$ and $\mathrm{M}$ were grouped together before SIMPER analysis was begun.

The main species responsible for the difference in assemblage structure between the SACW and the combination of $\mathrm{CW}$ and $\mathrm{M}(\mathrm{CW}+\mathrm{M})$ - the species that cumulatively accounted for $\sim 75 \%$ of the difference-were the Argentine anchoita, Atlantic cutlassfish, rough scad, piquitinga anchovy, and white snake mackerel (Thyrsitops lepidopoides), all of which were most abundant in SACW, and the Brazilian sardinella, flying gurnard, false pilchard (Harengula clupeola), American coastal pellona, and Atlantic thread herring (Ophistonema oglinum), all of which were most abundant in $\mathrm{CW}+\mathrm{M}$ (Table 6).

\section{Patterns of species association}

The resulting cluster for identifying species associations (Fig. 3) indicates the existence of 3 groups of species: group A, formed principally (70\% of species sampled) by species that were most abundant in the SACW (e.g., the Argentine anchoita, Atlantic cutlassfish, and 
咅竞

ชิ

赵

串 :

岁

फ

$\overbrace{}^{1}$

공

ป

ల్ల

S때

总

원

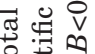

워 ब

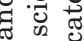

مิ

है I

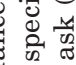

엉 엄

$+5$

$\frac{0}{0}$
正

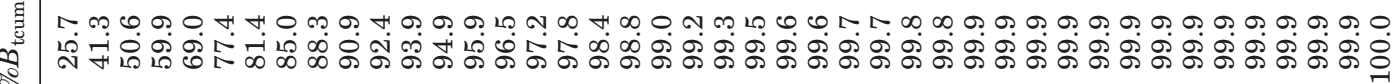

de

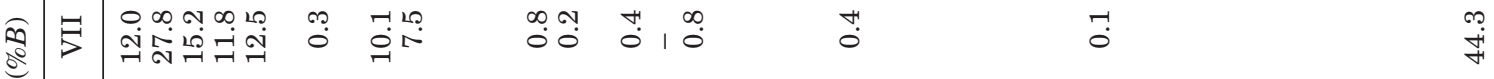

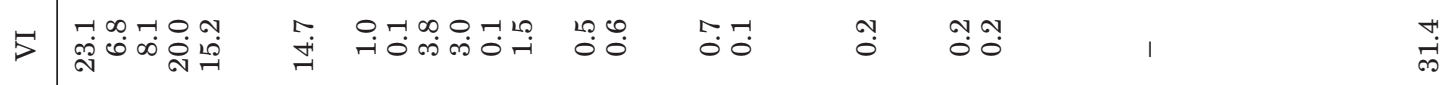

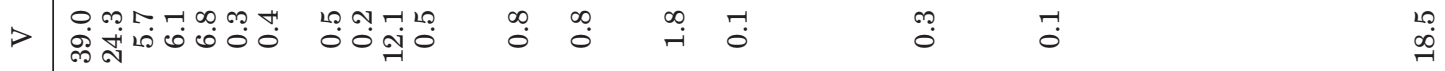

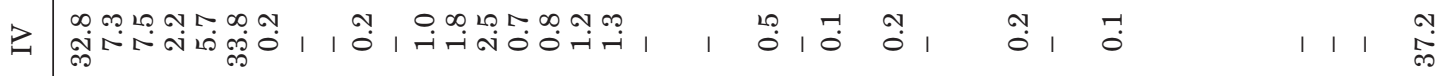

罒

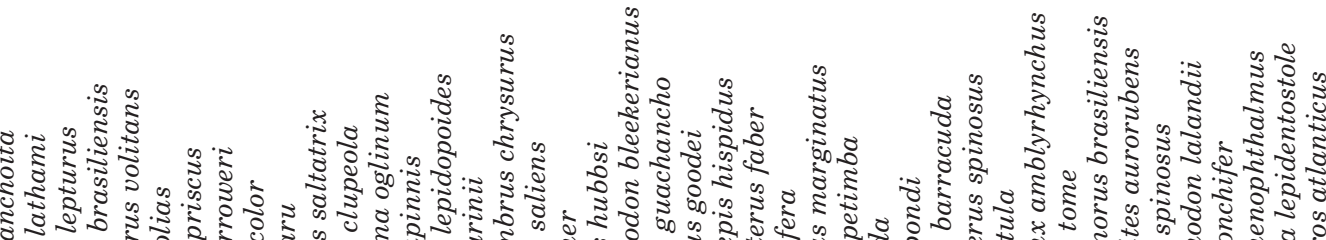

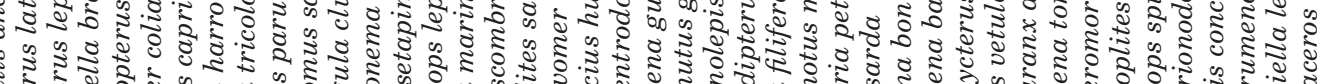

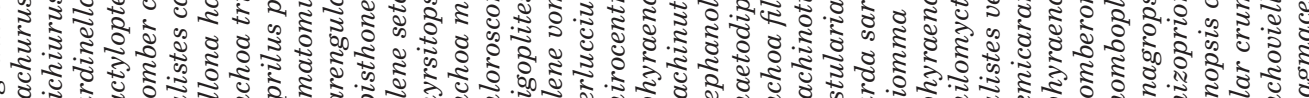
Af

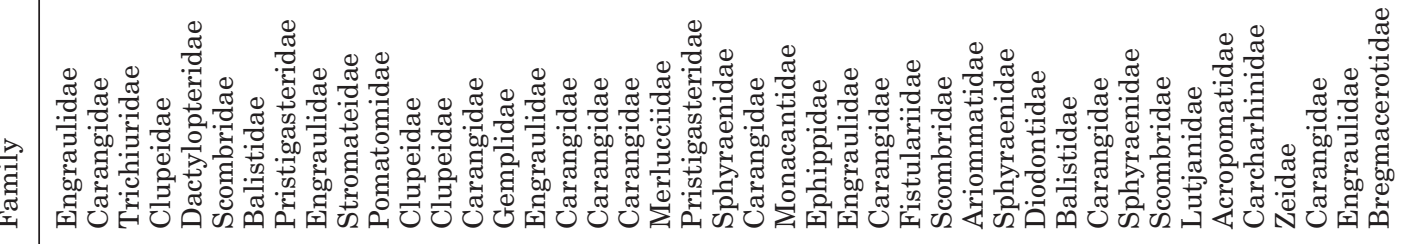




\section{Table 5}

Results of permutational multivariate analysis of variance to test for differences in fish assemblage structure among water masses (WM) and the ECOSAR III-VII cruises. Because of the unbalanced design, we used type-I sums of squares and tested the effect of one factor given the effect of another. The variance component of the interaction term was negative in both cases; therefore, it was pooled, and the data were re-analyzed. Significant $P$-values are presented in bold. $\mathrm{SS}=$ sum of squares; MS=mean sum of squares.

\begin{tabular}{lrcrrr}
\hline Source of variation & df & SS & MS & Pseudo- $F$ & $P$ \\
\hline WM, cruise | WM & & & & & \\
$\quad$ WM & 2 & 12,570 & 6285.2 & 14.29 & $\mathbf{0 . 0 3 2 5}$ \\
Cruise & 4 & 19,442 & 4860.4 & 1.14 & 0.1827 \\
$\quad$ Pooled & 71 & $3.04 \times 10^{9}$ & 4282.2 & & \\
$\quad$ Total & 77 & $3.36 \times 10^{9}$ & & & \\
Cruise, WM|cruise & & & & & \\
Cruise & 4 & 17,633 & 4408.1 & 10.29 & 0.3861 \\
WM & 2 & 14,380 & 7189.8 & 1.68 & $\mathbf{0 . 0 0 6 7}$ \\
Pooled & 71 & $3.04 \times 10^{9}$ & 4282.2 & & \\
$\quad$ Total & 77 & $3.36 \times 10^{9}$ & & & \\
& & & & & \\
\hline
\end{tabular}

\section{Table 6}

Summary of the analysis of similarity percentages to identify the most important species in distinguishing the assemblage that had, on average, higher biomass in the South Atlantic Central Water (SACW) than that of the assemblage that had, on average, higher biomass in the combination of the Coastal Water and Mixed Water $(\mathrm{CW}+\mathrm{M})$. Data used in this analysis were collected from the ECOSAR III-VII cruises. Abundance was measured as the mean

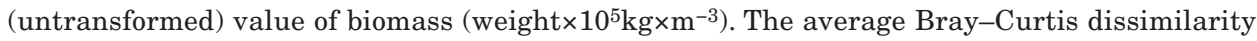
values between SACW and CW+M (Diss.), the contributions to between-group dissimilarities (Contrib\%), and the standard deviations (SD) of Bray-Curtis dissimilarities are presented. Higher Diss. and SD values indicate that the contribution of the species to the dissimilarity between the SACW and CW+M was reasonably consistent across all pairs of samples in the 2 groups. Only species that cumulatively contributed $\sim 90 \%$ to dissimilarity are shown.

\begin{tabular}{lccccc}
\hline & \multicolumn{2}{c}{ Abundance } & & & \\
\cline { 2 - 3 } Species & SAWC & CW+M & Diss. & SD & Contrib\% \\
\hline Argentine anchoita & 14.0 & 4.0 & 17.7 & 0.8 & 20.3 \\
Atlantic cutlassfish & 4.1 & 2.0 & 12.4 & 0.9 & 14.2 \\
Rough scad & 4.5 & 4.4 & 9.8 & 0.6 & 11.2 \\
Brazilian sardinella & 1.9 & 3.4 & 6.7 & 0.8 & 7.7 \\
Flying gurnard & 0.1 & 4.8 & 6.1 & 0.4 & 7.0 \\
False pilchard & 0.1 & 0.8 & 3.5 & 0.6 & 4.0 \\
American coastal pellona & 0.2 & 1.9 & 3.3 & 0.4 & 3.8 \\
Atlantic thread herring & 0.0 & 0.7 & 2.4 & 0.4 & 2.8 \\
Castin leatherjacket & 0.2 & 0.3 & 2.4 & 0.4 & 2.7 \\
Atlantic bumper & 0.1 & 0.3 & 2.2 & 0.4 & 2.5 \\
Piquitinga anchovy & 1.9 & 0.1 & 2.2 & 0.3 & 2.5 \\
Harvestfish & 0.1 & 1.2 & 2.2 & 0.4 & 2.5 \\
Atlantic moonfish & 0.8 & 0.0 & 2.1 & 0.4 & 2.5 \\
White snake mackerel & 0.3 & 0.2 & 2.0 & 0.6 & 2.3 \\
Gray triggerfish & 0.1 & 1.9 & 1.7 & 0.3 & 1.9 \\
Atlantic chub mackerel & 8.0 & 0.0 & 1.5 & 0.3 & 1.7 \\
Marini's anchovy & 0.1 & 0.1 & 1.4 & 0.3 & 1.3 \\
Bluefish & 0.8 & 0.0 & 0.9 & 0.2 & 1.0 \\
Great barracuda & 0.1 & 0.0 & 0.9 & 0.1 & 1.0 \\
& & & & & \\
\hline
\end{tabular}




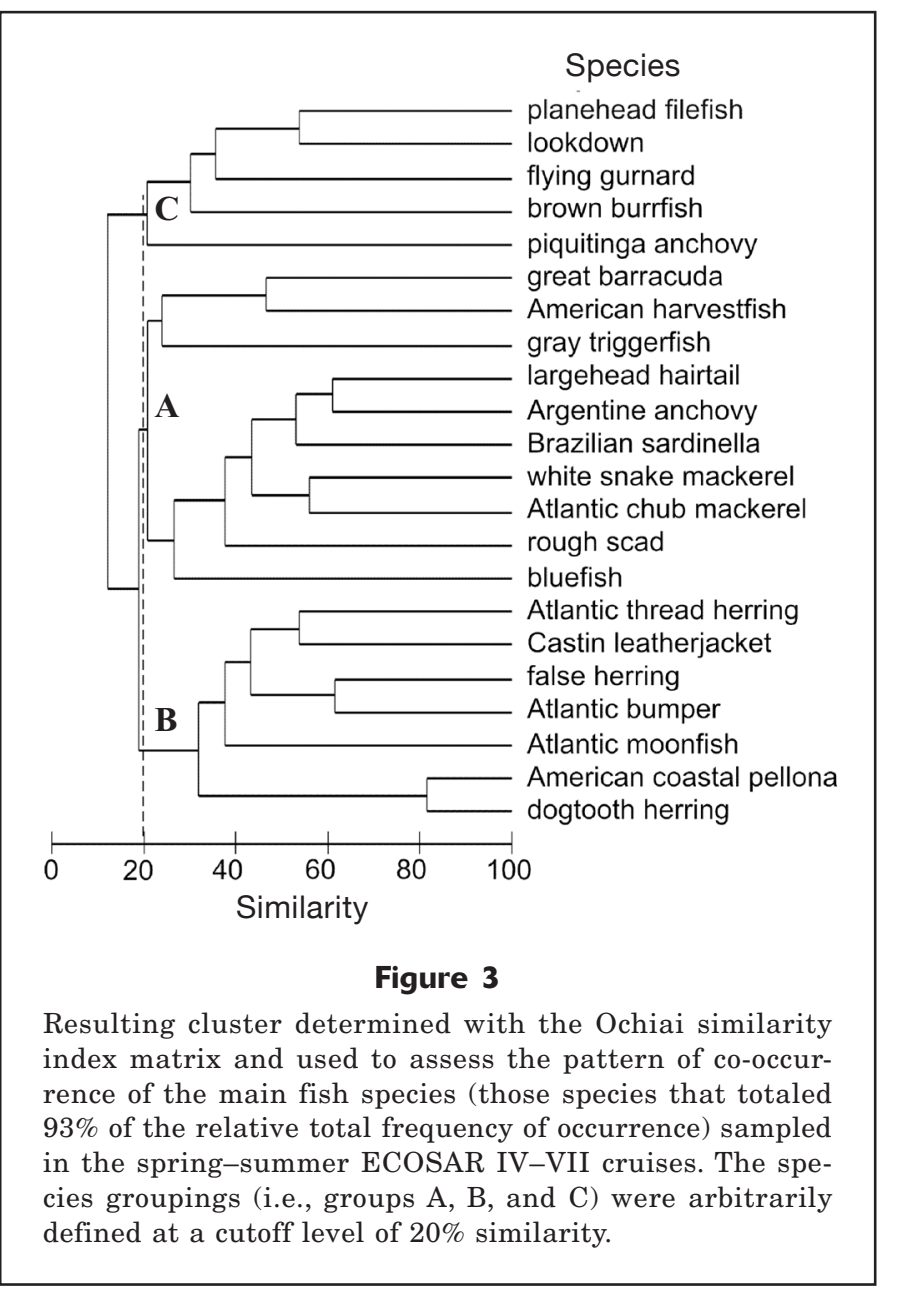

\section{Table 7}

Summary of results from analysis, conducted with the distance-based, nonparametric linear modeling (available in DistLM in the PERMANOVA+ add-on for the software PRIMER 6) of the relationship between multivariate structure of pelagic fish assemblages and oceanographic and spatial variables sampled during spring-summer ECOSAR IV-VII cruises in the southeastern Brazilian Bight. Data from these cruises (63 tows) were pooled because there was no interannual effect on the assemblage structure. The spatial variables were distance from shore (DS) and mean depth of the aggregation in the water column $\left(Z_{\mathrm{a}}\right)$. Models selected by the Bayesian information criterion and Akaike information criterion. Cumul.=cumulative percentage of the variability of the fish assemblage structure explained by the model. $\mathrm{SS}=$ sum of squares.

\begin{tabular}{lcccc}
\hline Variable & SS & Pseudo- $F$ & $P$-values & Cumul. (\%) \\
\hline $\mathrm{Z}_{\mathrm{a}}$ & 7771.2 & 1.818 & 0.0190 & 3.0 \\
$\mathrm{DS}$ & 9323.6 & 2.263 & 0.0036 & 7.0
\end{tabular}

rough scad) and were principally responsible for the differentiation of the SACW assemblage structure from the $\mathrm{CW}+\mathrm{M}$ assemblage structure (Table 6); group $\mathrm{B}$, formed mostly ( $85 \%$ of species sampled) by species that were more abundant in the $\mathrm{CW}+\mathrm{M}$ (e.g., the false pilchard, American coastal pellona, Atlantic thread herring, and castin leatherjacket [Oligoplites saliens]) and were relevant for distinguishing the assemblage structures of $\mathrm{CW}+\mathrm{M}$ and SACW (Table 5 ); and group C, a mixed grouping, composed of nodiagnostic species in SIMPER (Table 6) and of those species that were diagnostically abundant in either the $\mathrm{CW}+\mathrm{M}$ (e.g., flying gurnard) or the SACW (e.g., the piquitinga anchovy) assemblage.

\section{The effect of environmental and spatial factors on fish assemblage structure}

Because there was no significant variation in fish assemblage structure among the ECOSAR cruises (Table 5), data from all cruises were pooled to produce only one model for assessing the relationship between the variability in the assemblage structure and the oceanographic and spatial variables. The most parsimonious model was formed of 2 spatial variables: distance from shore and $Z_{\mathrm{a}}$ (Table 7 ). These variables explained $7 \%$ of total variation in fish assemblage structure. The resulting pattern among samples that was revealed on the constrained dbRDA ordination for this model (Fig. 4) indicates 2 clear gradients of shifts in the assemblage structure related to such variables. The vector of groupings of species (Fig. 3) on these gradients (Fig. 4) revealed 2 principal tendencies: 1) an increase in abundance of SACW-associated species with increasing $Z_{a}$ and a decreasing distance from shore and 2) an increase in abundance of species associated with $\mathrm{CW}+\mathrm{M}$ with decreasing $Z_{a}$ and an increasing distance from shore.

\section{Discussion}

Our findings reveal that the pelagic aggregations of fishes over the SBB shelf were dominated by highly abundant mid-trophic-level schooling species in association with predatory fishes (of which the Atlantic cutlassfish was the most representative). That result is consistent with the shelf pattern typically observed worldwide, including in the California Current (Litz et al., 2014), Colombia (Duarte and García, 2004), Humboldt Current (Fablet et al., 2012), Southern Brazil (Soares et al., 2005), and Benguela (Pecquerie et al., 2004). In our study, the biomass of the aggregations was dominated by Argentine anchoita, followed by rough scad, Atlantic chub mackerel, American coastal pellona, Brazilian sardinella, flying gurnard, and Atlantic cutlassfish, all of which may play a key role in the pelagic ecosystem of the SBB.

Such patterns of dominance and aggregations were consistent with those previously found for the 


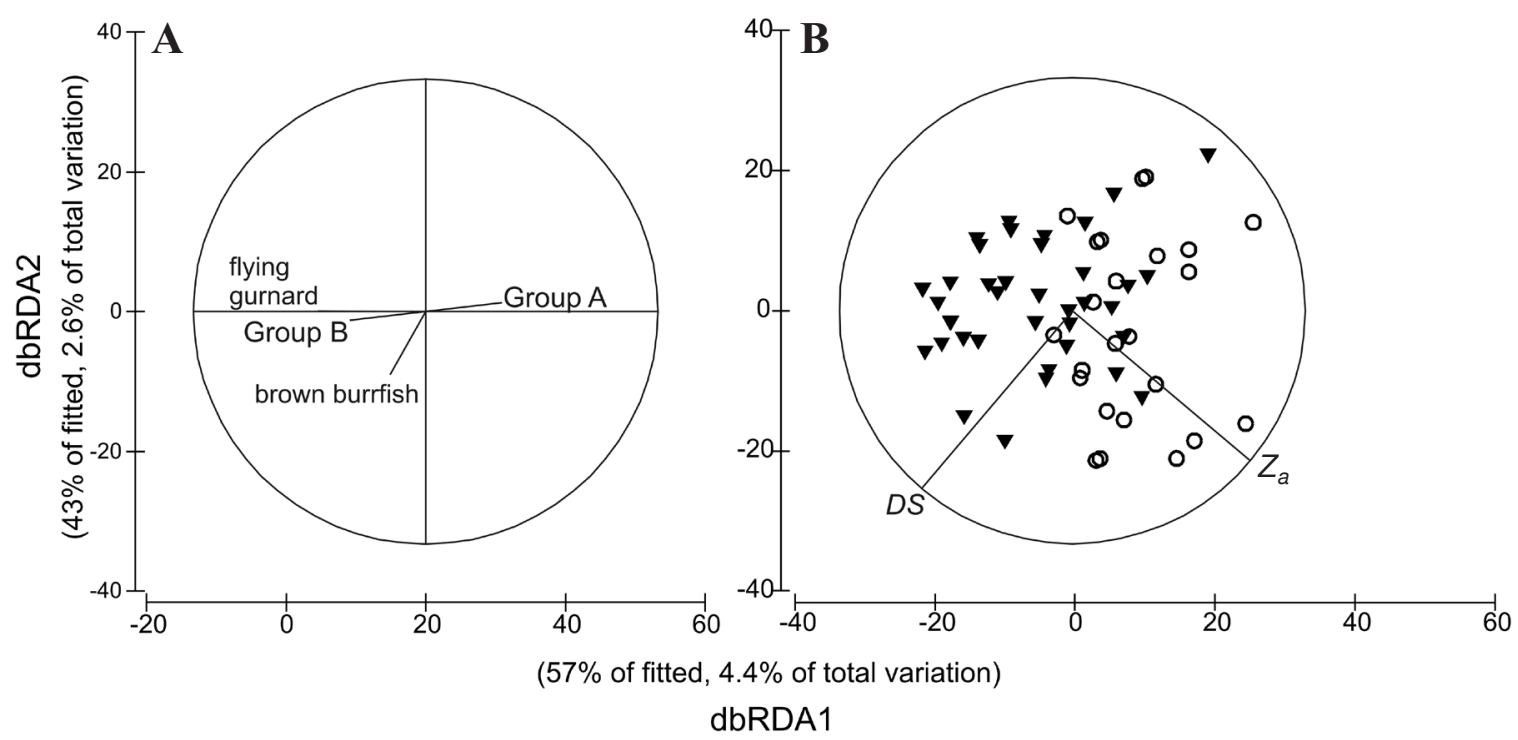

Figure 4

The first 2 axes from the distance-based redundancy analysis (dbRDA) that correlate the pelagic fish assemblage data collected during the spring-summer ECOSAR IV-VII cruises with (A) the species groups or species and (B) the explanatory variables (from the fitted model). $D S=$ distance from shore, $Z_{\mathrm{a}}=$ mean depth of the fish aggregation. Data from ECOSAR IV-VII cruises (63 tows) are pooled because there was no interannual effect on the assemblages. Samples were taken either from the South Atlantic Central Water (circles) or from the combination of the Coastal Water and Mixed Water (triangles). Group A and B were defined in cluster analyses (Fig. 3) and showed a Spearman correlation coefficient $\left|r_{\mathrm{SP}}\right| \geq 0.2$ with the axes. Group C species did not show clear association with a particular water mass; therefore, only those Group $\mathrm{C}$ species with correlations $\geq 0.2$ with either axis are plotted. Percentage explained by the axis (fitted) and total variation explained by the model are provided on the axes.

SBB and other areas of the SSAS. The Argentine anchoita forms large schools and is the dominant species in standing stocks of pelagic fishes and larval assemblages in the inner SBB (depths $<100 \mathrm{~m}$; this study; Katsuragawa et al., 2006), outer SBB (depths $>100$ m; Madureira et al., 2005), southern Brazilian shelf (Mello et al., 1992; Castello, 1998; Madureira et al., 2005), and coastal waters of Argentina (Hansen et al., 2001), supporting the idea that it is a keystone species of the SSAS (Bisbal, 1995; Castello, 1998; Hansen et al., 2001). Catches by industrial purse-seine fleets or during previous scientific surveys indicate that large schools of rough scad and Atlantic chub mackerel are common from the SBB to northern Argentina (Mello et al., 1992; Haimovici e al., 1994; Saccardo and Katsuragawa, 1995; Castro Hernández and Santana Ortega, 2000; Jaureguizar et al., 2006). The rough scad constitutes up to $85 \%$ of the standing stock of carangid larvae in the SBB (Katuragawa et al., 2006). Large bycatches of American coastal pellona and Atlantic cutlassfish are common in bottom trawl fisheries in the SBB (e.g., Paiva-Filho and Schmiegelow, 1986; Bernardes Júnior et al., 2011). The Brazilian sardinella is the most abundant fish in industrial purse-seine catches in the SBB (Vasconcellos and Gasalla, 2001), where its larvae are widely distributed (Katsuragawa et al., 2006).
The massive schools of flying gurnard juveniles detected in the water column were an uncommon and previously unreported phenomenon because this fish, which is morphologically adapted for living on soft bottoms (i.e., it has a relatively dorsoventrally flattened body and thoracic-placed pelvic fins to "walk" and forage over substrate; Sazima and Grossman, 2005), usually is captured in somewhat smaller numbers (generally $<1 \%$ of the total catch; e.g., Wood et al., 2009) or is observed in small groupings (of approximately 30 50 individuals) foraging on soft bottoms (Sazima and Grossman, 2005). Shoaling and crowding behavior has been reported for related species (e.g., the Oriental flying gurnard [Dactyloptena orientalis]; Noble, 1966) on the bottom but not for such species in the pelagic habit. It has been speculated that flying gurnard juveniles of such species cluster together in the water column to feed opportunistically on transitory and dense patches of zooplankton commonly present in spring and summer (Cordeiro ${ }^{7}$; Lopes et al., 2006b).

The aggregation structure in the SBB differed from the structure of aggregations in the pelagic zone off the

\footnotetext{
${ }^{7}$ Cordeiro, C. A. M. 2014. Personal commun. Departamento de Ciências do Mar, Univ. Federal de São Paulo, Santos, Brazil.
} 
SBB (i.e., at depths $>100 \mathrm{~m}$ ) as characterized during the REVIZEE midwater trawl surveys (Soares et al., 2005). Aggregations at depths of approximately $100 \mathrm{~m}$ were composed mainly of Argentine anchoita (89\% of the total catch), followed by American coastal pellona (7\%), Atlantic cutlassfish (7\%), white snake mackerel $(7 \%)$, and rough scad (1\%). Therefore, these aggregations were fairly similar to those in the SBB at depths $<100 \mathrm{~m}$. In depths of $100-200 \mathrm{~m}$, there was a strong shift in species abundance, and the aggregations there were primarily composed of a mesopelagic lightfish species (Maurolicus stehmani) (60\% of the total catch), together with the Argentine anchoita (18\%), striped codlet (Bregmaceros cantori; $7 \%$ ), and Atlantic cutlassfish $(4 \%)$.

Over the shelf break of the SBB (at depths of 200$800 \mathrm{~m}$ ), aggregations contained virtually no Clupeiformes (Soares et al., 2005) and consisted mostly of M. stehmani (96\% of the total catch), which were associated with a few species (e.g., Atlantic cutlassfish, and the largescale lizardfish [Saurida brasiliensis]). Such a replacement of Clupeiformes by mesopelagic fishes in the SBB is a typical pelagic shelf-slope gradient worldwide (e.g., Brodeur et al., 2003).

The aggregations found in the SBB were different from those that were hydroacoustically detected in a similar depth range $(<100 \mathrm{~m})$ off the central and northeastern coasts of Brazil. In central Brazil, they were composed of massive schools of the balloonfish (Diodon holocanthus [Madureira et al., 2004]) or of multiple species of triggerfishes (i.e., the unicorn filefish (Aluterus monoceros), gray triggerfish, queen triggerfish [Balistes vetula], and ocean triggerfish [Canthidermis sufflamen]). In northeastern Brazil, they were many fewer in number, compared with aggregations in southeastern Brazil, and they were composed of Myctophidae and Bothidae and did not contain schools of Clupeiformes (Vaske et al. ${ }^{8}$ ). In addition to the differences in efforts and spatiotemporal scales of sampling, these differences between the aggregations found in our study and those reported for the northeastern Brazil are most likely related to the pronounced zoogeographical contrast in fish fauna between the northeastern and southeastern coasts of Brazil (Joyeux et al., 2001).

Most of the records for tows carried out in areas identified as M most likely represented areas of mixing between CW and SACW, instead of between CW or SACW and Tropical Water. Tows conducted in M were carried out near the shoreline (mean distance: 37.2 $\mathrm{km}$ [32.6]), where the influences of CW and SACW are stronger than that of Tropical Water, which is located farther offshore $(\sim 80 \mathrm{~km}$ from the shoreline) during spring and summer (Castro, 2014).

Our results reveal that there were 2 groupings of

\footnotetext{
${ }^{8}$ Vaske, T., Jr., R. .P. Lessa, A. Monteiro, J. L. Bezerra, Jr, A. C. B. Ribeiro, L. Yokota, K. C. Moura, K. Lopez, and J. P. Firmino. 2005. Programa de Prospecção Acústica do Nordeste do Brasil (Levantamento da fauna com rede de meia água). REVIZEE Relatório Final, 54 p.
}

species that showed high occurrence and attained the highest biomass in specific water masses in the SBB in the spring-summer season: 1) the grouping that was strongly related to SACW and was composed mostly of Argentine anchoita, Atlantic cutlassfish, rough scad, piquitinga anchovy, white snake mackerel, and Atlantic chub mackerel and 2) the grouping that was formed mostly by Brazilian sardinella, flying gurnard, false pilchard, American coastal pellona, Atlantic thread herring, castin leatherjacket, and Atlantic bumper (Chloroscombrus chrysurus) and was strongly associated with CW and areas of mixing between CW and SACW.

The peak in biomass of each grouping followed the variation in location of their preferred water masses in relation to depth in the water column and distance from shore. The biomass of SACW-related assemblages reached its peak in deeper (Fig. 4) nearshore areas, and the biomass of $\mathrm{CW}+\mathrm{M}$-related assemblages reached its peak in waters farther offshore (Fig. 4), more surface layers. Such a pattern is consistent with the springsummer, complex hydrography of the SBB, and this hydrography generates spatial variations in temperature and salinity. Cyclonic eddies and meanders of the Brazil Current on the SBB are stronger in the spring and summer (Campos et al., 1995). Additionally, in this season, the large-scale high-pressure center in the South Atlantic makes winds blow from the northeast, resulting in stronger wind stress along the shore that leads to a surface offshore Ekman transport (Rodrigues and Lorenzetti, 2001). Both processes result in wide intrusion of the SACW frontal zone toward the inshore zones and in its persistence in deeper waters of the SBB just below the CW (Campos et al., 1995). Such a setting is more conspicuous near the shore between Cabo Frio and São Sebastião Island (Ciotti et al., 2014). Additionally, in the spring and summer, increased continental runoff may cause the $\mathrm{CW}$ to expand offshore and nearer the ocean surface on the SBB (Lopes et al., 2006a).

The consistent association of groups of species to specific water masses supports evidence that their life cycles are intimately tied to the typical water masses in the spring and summer at the SBB (Katsuragawa et al., 2006). Most of these species have a marked spawning activity in the spring and summer in the area (Katsuragawa et al., 2006), when the availability of planktonic food and the standing stock were at their highest levels (Lopes et al., 2006b). The growth of pelagic fish larvae occurs at a higher rate in specific temperature ranges, and those ranges differ among species (e.g., Matsuura, 1998). Therefore, this observed fidelity to habitat (water mass) may ensure suitable food supply within optimal temperature conditions for higher larval growth, survival, and recruitment, in turn, ensuring reproductive success (Matsuura, 1998; Jablonski and Legey, 2004). For example, the body condition of larvae of Argentine anchoita was highest in the SACW upwellings (Clemmesen et al., 1997). Results from studies based on observational data (Matsuura, 1998; Jablonski and Legey, 2004) and simulated data (Dias et al., 
2014) have indicated that the reproductive activity and larval growth rates of Brazilian sardinella were higher at higher temperatures $\left(\sim 21-27^{\circ} \mathrm{C}\right)$ of $\mathrm{CW}$ in the SBB.

Although some species, such as the flying gurnard, Brazilian sardinella, and piquitinga anchovy, have been more abundant in a specific water mass, they cooccurred more frequently with species that were more abundant in another water mass. For example, although the Brazilian sardinella was more abundant in $\mathrm{CW}+\mathrm{M}$, it occurred more frequently with species more abundant in SACW. This result reveals that the species show a high flexibility with environmental variability and that their abundance patterns are characterized by gradients (instead of fixed points) that follow the environmental gradient defined from one water mass through another.

This study had 3 limitations. First, the number of fish samples from different water masses was not balanced within each survey and among the ECOSAR cruises; this difference in sampling may be one of the reasons for the lack of significant differences in fish structure among the different cruises (i.e., different years) and along the latitudes.

Second, although our large data set ensured a general overview of the species composition and abundance of pelagic fish aggregations in the SBB, we understand that our data set may be biased with regard to estimates of these attributes for the whole SBB pelagic nekton (i.e., the pool of organisms both inside and outside aggregations) because 1) it is unclear whether the adopted spatial scale for sampling best represented the variance in the biomass of populations because there was no previous study to inform it, 2) sampling randomness was not adopted, and 3) many pelagic large fast-swimming predators, such as sharks, the dolphinfish (Coryphaena hippurus), and the skipjack tuna (Katsuwonus pelamis), were poorly represented or not captured; despite being common in SBB aggregations (Rossi-Wongtschowski et al., 2014), such predators were not susceptible to midwater trawls (Brodeur et al., 2005). Therefore, it is strongly recommended that a future study should be based on information that helps to specify the best sampling spatial scale, on multiple sampling gear, and on a sampling design balanced in relation to cruises, latitudes, and water masses.

Third, although significant, the effect of the spatial variation of water masses explained little $(7 \%)$ of the total variation in fish assemblage structure. The large body of undetermined effects in the data may result from important but unconsidered factors for recruitment success, for maintenance of stock size, and ultimately for spatiotemporal distribution of assemblages, such as turbulence, currents (Thomson et al., 1992), zooplankton availability, abundance, and productivity (Longhurst and Pauly, 2007), and especially the age of a population and its reproductive structure (Fablet et al., 2012; Carvalho and Castello, 2013; Dias et al., 2014).

Satellite-derived data for surface levels of chlorophyll- $a$ during the periods of this study, used as a proxy for phytoplankton abundance, did not show significant effect on fish assemblage structure and therefore contributed to the large body of undetermined effects. For future studies, we recommended that phytoplankton be measured concomitantly with the tows, at the same depth of tow or as close as possible. Such simultaneous measurements should also be valid for other food resources, such as zooplankton. This concurrent measurement of phytoplankton would increase the possibility of detecting the recurrent and structuring role of plankton on pelagic assemblages of fishes (Longhurst and Pauly, 2007), of which the bulk of species are planktivorous. Other potential causes for this lack of significant effect are 1) that the spatial resolution of chlorophyll- $a$ measurement may have been low and incompatible with the spatial scale of tows or 2) that fish populations may have a delayed response to phytoplankton and subsequent zooplankton peaks (Litz et al., 2014).

In conclusion, small pelagic fish populations dominated the multispecific aggregations over the SBB in spring and summer, and the spatiotemporal variability of the aggregations fitted well with the spring-summer, hydrographically complex structure of the SBB. Two species groupings were reliably linked to either the $\mathrm{CW}+\mathrm{M}$ or the SACW. Such conclusions may support the adoption of an EBFM for the SBB, which has been heavily affected by fishing and activities related to oil and gas extraction.

For conservation purposes, for example, the mapping of the species assemblages in SBB water masses through remote sensing may be a useful indicator of the spatial variability of pelagic fish assemblages. The identification of areas with high density of Argentine anchoita will be particularly important for managing the potential, near-future exploitation of the SBB stocks of this species, stocks that are in almost-virginal condition (Madureira et al., 2009). The management of this stock will deserve particular attention because the Argentine anchoita population of the SBB exhibits a lower individual growth rate and a higher natural mortality rate than does the population that inhabits the southern Brazilian shelf (Carvalho and Castello, 2013). To better understand and forecast human-induced impacts in the SBB, an effective EBFM is needed and should include future efforts 1) to accurately estimate pelagic fish biomass and identify pelagic trophic groups to model food-web dynamics and 2) to investigate the relationship of fish assemblages and population structure and dynamics with water masses, physical forcings, and distribution of food availability to improve the predictability of multispecies multivariate models.

\section{Acknowledgments}

We are especially grateful to the Brazilian Institute of Environment and Renewable Natural Resources for funding the cruises for this study, and we thank the officers and crew of the ship Atlântico Sul, the staff 
of the Fishing and Hydroacoustic Technology Laboratory, Federal University of Rio Grande, and the staff of the Laboratory of Growth and Ichthyology, Oceanography Institute of the University of São Paulo, for on-board work during cruises. We also thank D. Sasaki for producing the maps, M. Rodrigues da Costa, and A. Vaz dos Santos for their constructive contributions to an early manuscript version of this article, and 3 referees for their great contributions for improving the manuscript.

\section{Literature cited}

Anderson, M. J., R. N. Gorley, and K. R. Clarke. 2008. PERMANOVA for PRIMER: guide to software and statistical methods, 214 p. PRIMER-E Ltd., Plymouth, UK.

Bernardes Júnior, J. J., J. L. Rodrigues Filho, J. O. Branco, and J. R. Verani.

2011. Spatiotemporal variations of the ichthyofaunal structure accompanying the seabob shrimp, Xiphopenaeus kroyeri (Crustacea: Penaeidae), fishery in important fishery areas of the Santa Catarina shore, Brazil. Zoologia 28:151-164. Article

Bisbal, G. A.

1995. The Southeast South American shelf large marine ecosystem: evolution and components. Mar. Policy 19:21-38. Article

Brodeur, R. D., J. P. Fisher, R. L. Emmett, C. A. Morgan, and E. Casillas.

2005. Species composition and community structure of pelagic nekton off Oregon and Washington under variable oceanographic conditions. Mar. Ecol. Prog. Ser. 298:41-57. Article

Brodeur, R. D., W. G. Pearcy, and S. Ralston.

2003. Abundance and distribution patterns of nekton and micronekton in the northern California Current transition zone. J. Oceanogr. 59:415-434. Article

Burnham, K. P., and D. R. Anderson.

2002. Model selection and multimodel inference: a practical information-theoretic approach, 2nd ed., 488 p. Springer-Verlag, New York.

Campos, E. J. D., J. E. Gonçalves, and Y. Ikeda.

1995. Water mass characteristics and geostrophic circulation in the South Brazil Bight: summer of 1991. J. Geophys. Res., C 100:18537-18550. Article

Carvalho, F. M., and J. P. Castello.

2013. Argentine anchovy (Engraulis anchoita) stock identification and incipient exploitation in southern Brazil. Lat. Am. J. Aquat. Res. 41:820 - 827.

Castello, J. P., R. P. Habiaga, J. C. Amaral, and I Lima Jr. 1991. Prospecção hidroacústica e avaliação da biomassa de sardinha e anchoita, na região sudeste do Brasil (Outubro/novembro de 1998). Publ. Esp. Inst. Oceanogr. $8: 15-29$.

Castello, J. P.

1998. Teleósteos pelágicos. In Os ecossistemas costeiro e marinho do extremo sul do Brasil (U. Selliger, C. Odebrect, and J. P. Castello eds.). p. 137-143. Editora Ecoscientia, Rio Grande, Brazil.

Castro, B. M.

2014. Summer/winter stratification variability in the central part of the South Brazil Bight. Cont. Shelf Res. 89:15-23. Article
Castro, B. M., and L. B. Miranda.

1998. Physical oceanography of the western Atlantic continental shelf located between $4^{\circ} \mathrm{N}$ and $34^{\circ} \mathrm{S}$ coastal segment $\left(4^{\circ} \mathrm{W}\right)$. In The Sea, vol. 11 (A. R. Robinson and K. H. Brink, eds.), p. 209-251. John Wiley \& Sons, New York.

Castro Hernández, J. J., and A. T. Santana Ortega.

2000. Synopsis of biological data on the chub mackerel (Scomber japonicus Houttuyn, 1782). FAO Fish. Synop. 157, 77 p. FAO, Rome.

Ciotti, A. M., M. Mahiques, and O. O. Möller.

2014. The meridional gradients of the S-SE Brazilian continental shelf: introduction to the special volume. Cont. Shelf Res. 89:1-4. Article

Clarke, K. R., and R. M. Warwick.

2001. Change in marine communities: an approach to statistical analysis and interpretation, $2^{\text {nd }}$ ed., $172 \mathrm{p}$. PRIMER-E, Plymouth, UK.

Clemmesen, C. M., R. P. Sánchez, and C. L. B. RossiWongtschowski.

1997. A regional comparison of nutritional condition of SW Atlantic anchovy larvae (Engraulis anchoita) based on RNA/DNA ratios. Arch. Fish. Mar. Res. 45:17-43.

Cury, P., A. Bakun, R. J. M. Crawford, A. Jarre, R. A. Quinoñes, L. J. Shannon, and H. M. Verheye.

2000. Small pelagics in upwelling systems: patterns of interaction and structural changes in "wasp-waist" ecosystems. ICES J Mar. Sci. 57:603-618. Article

Curtin, R., and R. Prellezo.

2010. Understanding marine ecosystem based management: a literature review. Mar. Policy 34:821-830. Article

Dias, D. F., L. P. Pezzi, D. F. M. Gherardi, and R. Camargo.

2014. Modeling the spawning strategies and larval survival of the Brazilian sardine (Sardinella brasiliensis). Prog. Oceanogr. 123:38-53. Article

Diggle, P. J., and P. J. Ribeiro.

2007. Model-based geostatistics, 232 p. Springer-Verlag, New York.

Dormann, C. F., J. Elith, S. Bacher, C. Buchmann, G. Carl, G. Carré, J. R. G. Marquéz, B. Gruber, B. Lafourcade, P. J. Leitão, T. Münkemüller, C. McClean, P. E. Osborne, B. Reineking, B. Schröder, A. K. Skidmore, D. Zurell, and S. Lautenbach.

2013. Collinearity: a review of methods to deal with it and a simulation study evaluating their performance. Ecography 36:27-46. Article

Duarte, L. O., and C. B. Garcia.

2004. Trophic role of small pelagic fishes in a tropical upwelling ecosystem. Ecol. Model. 172:323-338. Article

Fablet, R., P. Gay, S. Peraltilla, C. Peña, R. Castillo, and A. Bertrand.

2012. Bags-of-Features for fish school cluster characterization in pelagic ecosystems: application to the discrimination of juvenile and adult anchovy (Engraulis ringens) clusters off Peru. Can. J. Fish. Aquat. Sci. 69:13291339. Article

Fletcher, D. J., and A. J. Underwood.

2002. How to cope with negative estimates of components of variance in ecological field studies. J. Exp. Mar. Biol. Ecol. 273:89-95. Article

Freire, R. R., and J. C. P. Vasconcellos.

2011. Cálculo de área de poligonais geodésicas ou loxodrômicas sobre o elipsóide do sistema geodésico WGS-84. Rev. Bras. Cartog. 63:555-563. 
Haimovici, M., A. S. Martins, J. L. Figueiredo, and P. C. Vieira. 1994. Demersal bony fish of the outer shelf and upper slope of the southern Brazil subtropical convergence ecosystem. Mar. Ecol. Prog. Ser. 108:59-77.

Hansen, J. E., P. Martos, and A. Madirolas.

2001. Relationship between spatial distribution of the Patagonian stock of Argentine anchovy, Engraulis anchoita, and sea temperatures during late spring to early summer. Fish. Oceanogr. 10:193-206. Article

Harding, J. A., A. J. Ammann, and R. B. MacFarlane.

2011. Regional and seasonal patterns of epipelagic fish assemblages from the central California Current. Fish. Bull. 109:261-281.

Jablonski, S., and L. F. L. Legey.

2004. Quantifying environmental effects on the recruitment of the Brazilian sardine (Sardinella brasiliensis), 1977-1993. Sci. Mar. 68:385-398.

Jaureguizar, A. J., R. Menni, C. Lasta, and R. Guerrero.

2006. Fish assemblages of the northern Argentine coastal system: spatial patterns and their temporal variations. Fish. Oceanogr. 15:326-344. Article

Joyeux, J. C., S. R. Floeter, C. E. L. Ferreira, and J. L. Gasparini.

2001. Biogeography of tropical reef fish: the South Atlantic puzzle. J. Biogeogr. 28:831-841. Article

Katsuragawa, M., J. H. Muelbert, and J. F. Dias.

2006. O ictioplâncton na região entre o Cabo de São Tomé (RJ) e o Chuí (RS). In $\mathrm{O}$ ambiente oceanografico da plataforma continental e do talude na região sudeste-sul do Brasil (C. L. D. B. Rossi-Wongtschowski and L. S.-P. Madureira, eds.), p. 350-446. Edusp, São Paulo., Brazil. Legendre, P., and L. Legendre.

1998. Numerical ecology, $2^{\text {nd }}$ ed., 852 p. Elsevier Science BV, Amsterdam.

Litz, M. N. C., R. L. Emmett, P. J. Bentley, A. M. Claiborne, and C. Barceló.

2014. Biotic and abiotic factors influencing forage fish and pelagic nekton community in the Columbia River plume (USA) throughout the upwelling season 19992009. ICES J Mar. Sci. 71:5-18 Article

Longhurst, A. R., and D. Pauly.

2007. Ecologia dos oceanos tropicais, 424 p. Edusp, São Paulo, Brazil.

Lopes, R. M., M. Katsuragawa, J. F. Dias, M. A. Montú, J. H. Muelbert, C. Gorri, and F. P. Brandini.

2006b. Zooplankton and ichthyoplankton distribution on the southern Brazilian shelf: an overview. Sci. Mar. 70:189-202.

Lopes, R. M., M. A. Montú, C. Gorri, E. Muxagata, L. Miyashita, and L. P. Oliveira.

2006a. O zooplâncton marinho da região entre o Cabo de São Tomé (RJ) e o Chuí (RS). In O ambiente oceanografico da plataforma continental e do talude na região sudeste-sul do Brasil (C. L. D. B. Rossi-Wongtschowski and L. S. Madureira, eds.), p. 265-358. Edusp, São Paulo, Brazil.

Madureira, L. S. P., J. P. Castello, C. Prentice-Hernández, M. I. Queiroz, M. L. Espírito Santo, W. H. Ruiz, P. R. Abdallah, J. E. Hansen, M. I Bertolotti, E. Manca, M. I. Yeannes, N. Avdalov, and F. Amorín.

2009. Current and potential alternative food uses of the Argentine anchoita (Engraulis anchoita) in Argentina, Uruguay and Brazil. In Fish as feed inputs for aquaculture: practices, sustainability and implications (M.
R. Hasan and M. Halwart, eds.), p. 269-287. FAO Fish. Aquacult. Tech. Pap. 518. FAO, Rome.

Madureira, L. S.-P., R. G. P. Habiaga, A. Gonçalves, A. B. Greig, A. C. Duvoisin, C. F. Soares; I. Y. Fuse, F. G. Caldeira, L. R. Carvalho; S. C. Weigert, P. A. Saldo, and C. S. Ferreira. 2004. Prospecção de recursos pelágicos por método hidroacústico na plataforma, talude e região oceânica da costa Central do Brasil. Série Documentos REVIZEE: Score Sul, 56 p. Instituto Oceanográfico-USP, São Paulo, Brazil.

Madureira, L. S. P., M. C. Vasconcellos, S. C. Weigert, R. P. Habiaga, M. Pinho, C. S. Ferreira, A. C. Duvoisin, C. F. Soares, and M. A. Bruno.

2005. Distribuição, abundância e interações ambientais de espécies pelágicas na região sudeste e sul do Brasil, entre Cabo de São Tomé (RJ) e o Chuí (RS). In Prospecção de recursos pesqueiros pelágicos na Zona Econômica Exclusiva da região sudeste-sul do Brasil: hidroacústica e biomassas (L. S. P. Madureira and C. L. D. B. RossiWongtschowski, eds.), p. 63-131. Instituto Oceanográfico-USP, São Paulo, Brazil.

Matsuura, Y.

1998. Brazilian sardine (Sardinella brasiliensis) spawning in the southeast Brazilian Bight over the period 1976-1993. Rev. Bras. Oceanogr. 46:33-43.

Mello, R. M., J. P. Castello, and K. M. F. Freire.

1992. Asociación de espécies pelágicas marinas en el sur de Brasil durante invierno y primavera. Frente Mar., Sec. A, 11: 63-69.

Möllmann, C., C. Folke, M. Edwards, and A. Conversi.

2015. Marine regime shifts around the globe: theory, drivers and impacts. Phil. Trans. R. Soc. B. 370:1-5. Article

Noble, A.

1966. Note on the food of flying gurnard, Dactyloptena orientalis (Cuvier). J. Mar. Biol. Assoc. India. 8(2):368-369.

Paiva-Filho, A. M., and J. M. M. Schmiegelow.

1986. Estudo sobre a ictiofauna acompanhante da pesca do camarão sete-barbas (Xyphopenaeus kroyeri) nas proximidades da Baía de Santos-SP. I.-Aspectos quantitativos. Bol. Inst. Oceanogr. 34:79-85.

Pecquerie L., L. Drapeau, P. Fréon, J. C. Coetzee, R. W. Leslie, and M. H. Griffiths.

2004. Distribution patterns of key fish species of the southern Benguela ecosystem: an approach combining fishery-dependent and fishery-independent data. Afr. J. Mar. Sci. 26:115-139. Article

Podani, J.

2000. Introduction to the exploration of multivariate biological data, 407 p. Backhuys Publishers, Leiden, Netherlands.

$\mathrm{R}$ Core Team.

2014. R: a language and environment for statistical computing. R Foundation for Statistical Computing, Vienna, Austria. [Available at website, accessed April 2014.]

Rocha, G. R. A., and C. L D. B. Rossi-Wongtschowski.

1998. Demersal fish community on the inner shelf of Ubatuba, Southeastern Brazil. Rev. Bras. Oceanogr. 46:93-109. Article

Rodrigues, R. R., and J. A. Lorenzetti.

2001. A numerical study of the effects of bottom topography and coastline geometry on the southeast Brazilian coastal upwelling. Cont. Shelf Res. 21:371-394. Article 
Rossi-Wongtschowski, C. L. D. B., E. Y. Muto, and L.S.H. Soares.

2008. Ictiofauna. In Oceanografia de um ecossistema subtropical: plataforma de São Sebastião, SP (A.M.S. P. Vanin, ed.), p. 381-404. Edusp, São Paulo, Brazil.

Rossi-Wongtschowski, C. L. D. B., A. M. Vaz-dos-Santos, and C. C. Siliprandi.

2014. Checklist of the marine fishes collected during hydroacoustic surveys in the southeastern Brazilian Bight from 1995 to 2010. Arq. Zool. 45:73-88.

Saccardo, S. A., and M. Katsuragawa.

1995. Biology of the rough scad Trachurus lathami, on the southeastern coast of Brazil. Sci. Mar. 59:265-277.

Sazima, C., and A. Grossman.

2005. A non-digging zoobenthivorous fish attracts two opportunistic predatory fish associates. Neotrop. Ichthyol. 3:445-448. Article

Soares, C. F., L. S. P. Madureira, L. P. Habiaga, L. D. Laurino, C. S. Ferreira, and S. C. Weigert.

2005. Caracterização dos ecotipos detectados durante os cruzeiros de prospecção pesqueira acústica entre Cabo de São Tomé (RJ) e Chuí (RS). In Prospecção de recursos pesqueiros pelágicos na Zona Econômica Exclusiva da região sudeste-sul do Brasil: hidroacústica e biomassas
(L. S. P. Madureira and C. L. D. B. Rossi-Wongtschowski, eds.), p. 17-61. Instituto Oceanográfico-USP, São Paulo, Brazil.

Speckman, S. G., J. F. Piatt, C. V. Minte-Vera, and J. K. Parrish. 2005. Parallel structure among environmental gradients and three trophic levels in a subartic estuary. Prog. Oceanogr. 66:25-65. Article

Thomson K. A., W. J. Ingraham, M. C. Healey, P. H. LeBlond, C. Groot, and C. G. Healey.

1992. The influence of ocean currents on latitude of landfall and migration speed of sockeye salmon returning to the Fraser River. Fish. Oceanogr. 1:163-179. Article

Vasconcellos, M. C., and M. A. Gasalla.

2001. Fisheries catches and the carrying capacity of marine ecosystems in southern Brazil. Fish. Res. 50:279-295. Article

Willis, T. J., and M. J. Anderson.

2003. Structure of cryptic reef fish assemblages: relationships with habitat characteristics and predator density. Mar. Ecol. Progr. Ser. 257:209-221. Article

Wood, A. J. M., J. S. Collie, and J. A. Hare.

2009. A comparison between warm-water fish assemblages of Narragansett Bay and those of Long Island Sound waters. Fish. Bull. 107:89-100. 